\title{
Catalytic Reduction of Dinitrogen to Ammonia and Hydrazine Using Iron- Dinitrogen Complexes Bearing Anionic Benzene-Based PCP-type Pincer Ligands
}

Shogo Kuriyama, ${ }^{\dagger}$ Takeru Kato, ${ }^{\dagger}$ Hiromasa Tanaka, ${ }^{\ddagger}$ Asuka Konomi, ${ }^{\S}$ Kazunari Yoshizawa, ${ }^{*}$ and Yoshiaki Nishibayashi* ${ }^{\dagger}$

'Department of Applied Chemistry, School of Engineering, The University of Tokyo, Hongo, Bunkyo-ku, Tokyo 1138656, Japan.

Email: ynishiba@g.ecc.u-tokyo.ac.jp

tSchool of Liberal Arts and Sciences, Daido University, Minami-ku, Nagoya 457-8530, Japan.

${ }^{\S}$ Institute for Materials Chemistry and Engineering, Kyushu University, Nishi-ku, Fukuoka 819-0395, Japan.

Email: kazunari@ms.ifoc.kyushu-u.ac.jp

\begin{abstract}
Among synthetic models of nitrogenases, iron-dinitrogen complexes with a Fe-C bond have attracted increasing attention in recent years. Here we report the synthesis of square-planar iron(I)-dinitrogen complexes supported by anionic benzene-based PCP- and POCOP-type pincer ligands as carbon donors. These complexes catalyze the formation of ammonia and hydrazine from the reaction of dinitrogen $(1 \mathrm{~atm})$ with a reductant and a proton source at $-78{ }^{\circ} \mathrm{C}$, producing up to 252 equiv of ammonia and 68 equiv of hydrazine (388 equiv of fixed $\mathrm{N}$ atom) based on the iron atom of the catalyst. Anionic iron(0)-dinitrogen complexes, considered an essential reactive species in the catalytic reaction, are newly isolated from the reduction of the corresponding iron(I)-dinitrogen complexes. This study examines their reactivity using experiments and DFT calculations.
\end{abstract}


Biological nitrogen fixation relies on nitrogenase enzymes that catalyze the reduction of an atmospheric pressure of dinitrogen into ammonia at ambient temperature using electrons and protons. ${ }^{1}$ The active site of the molybdenum nitrogenase, FeMo-co, has been established as a molybdenum-iron-sulfur cluster with a central carbide. ${ }^{2-4}$ A feature of the carbide is highly covalent bonds with iron atoms, which cannot be exchanged during the catalytic process. ${ }^{5,6}$ Recent studies suggest that a possible $\mathrm{N}_{2}$ coordination site is the iron atom bound to the carbon atom following the cleavage of the Fe-S bond. ${ }^{7-12}$ However, the structure containing the $\mathrm{N}_{2}$-derived ligands is controversial. ${ }^{13,14}$ Although carbide seems to stabilize the metal-sulfur cluster during catalysis, ${ }^{5,6}$ the exact role of the carbon atom in the reaction mechanism with molybdenum nitrogenase has been unclear until now.

Iron-dinitrogen complexes, supported by various carbon donor ligands, have been model compounds of the active site of nitrogenases (Figure 1a) to gain insight into the influence of the carbon atom on the reactivity and the structure. ${ }^{15-32}$ Although their reactivity toward nitrogen fixation has been investigated, $25,26,31,32$ there are limited examples of the successful application of these complexes as catalysts to reduce dinitrogen into ammonia and hydrazine. ${ }^{20-22}$

(a)
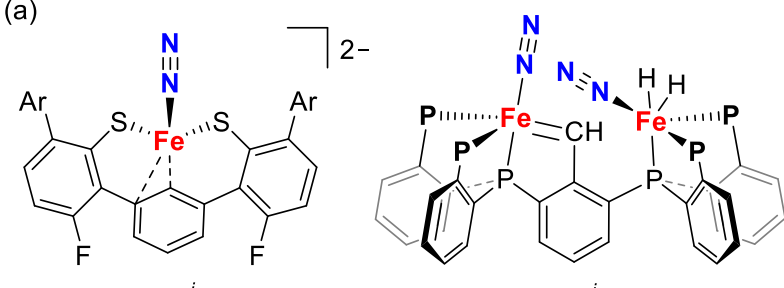

$\mathrm{Ar}=2,4,6-{ }^{i} \mathrm{Pr}_{3} \mathrm{C}_{6} \mathrm{H}_{2}$ Holland

$\mathbf{P}=\mathrm{P}^{i} \mathrm{Pr}_{2}$
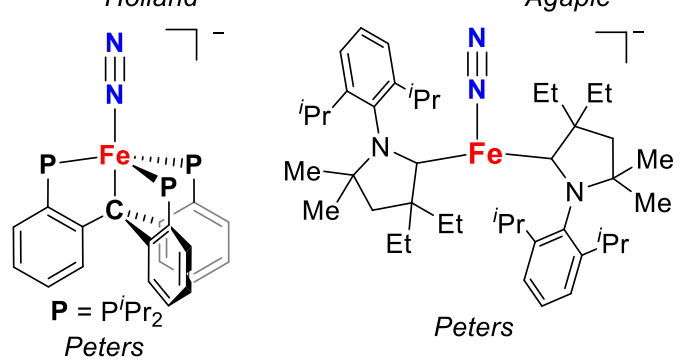

(b)

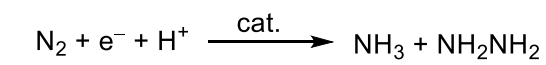

cat.

Our previous work

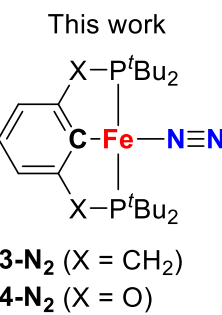

Figure 1. (a) Selected recent examples of iron-dinitrogen complexes with an $\mathrm{Fe}-\mathrm{C}$ bond.

(b) Catalytic reduction of dinitrogen with reductant and proton into ammonia and hydrazine by iron-dinitrogen complexes bearing anionic pincer ligands. 
The catalytic transformation of dinitrogen into ammonia and hydrazine using homogeneous transition-metal complexes under mild reaction conditions has been studied intensively to develop efficient catalysts for nitrogen fixation. ${ }^{33-55}$ In a 2016 paper, we reported the catalytic formation of ammonia and hydrazine from the reaction of dinitrogen gas with a reductant and a proton source at $-78^{\circ} \mathrm{C}$ in the presence of iron-dinitrogen complexes bearing anionic pyrrole-based PNP-type pincer ligands (1-N $\mathbf{N}_{\mathbf{2}}$ in Figure 1b). ${ }^{57}$ More recently, we achieved higher catalytic activity with an irondinitrogen complex bearing a 3,4-dimethylpyrrole-based PNP-type pincer ligand due to the electrondonating property of the dimethyl groups at the pyrrole moiety, which promotes the first protonation step of the coordinated dinitrogen ligand on the iron atom (2-N2 in Figure 1b). ${ }^{58}$ Modeling the importance of carbon atoms in nitrogenases due to the strongly $\sigma$-donating anionic benzene-based ligand, ${ }^{59}$ we designed novel iron-dinitrogen complexes that feature anionic benzene-based PCP-and POCOP-type pincer ligands as catalysts to reduce dinitrogen into ammonia and hydrazine under mild

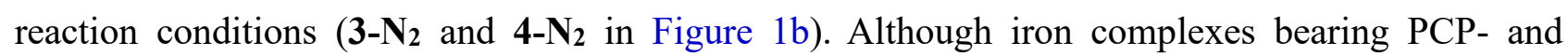
PXCXP-type pincer ligands have been developed in several studies, ${ }^{60-63}$ none of them has been applied as catalysts for nitrogen fixation. This paper establishes that the newly synthesized irondinitrogen complexes, featuring benzene-based PCP-type pincer ligands, function as the most active iron catalysts to reduce dinitrogen to ammonia and hydrazine under mild reaction conditions.

The reaction of $\left[\mathrm{FeBr}_{2}(\mathrm{THF})_{2}\right]$ with Li-PCP $\quad(\mathrm{PCP}=2,6$-bis(di-tertbutylphosphinomethyl)phenyl), which was generated in situ from Br-PCP and ${ }^{n} \mathrm{BuLi}$ in tetrahydrofuran (THF) at room temperature for $4 \mathrm{~h}$, provided $[\mathrm{FeBr}(\mathrm{PCP})](3-\mathrm{Br})$ in $56 \%$ yield (Scheme 1). An iron-iodide complex bearing a POCOP ligand [FeI(POCOP)] (4-I, POCOP = 2,6bis(di-tert-butylphosphinito)phenyl) was obtained in $75 \%$ yield by a similar method (Scheme 1). Single-crystal X-ray diffraction analysis (XRD) determined the square-planar geometries of 3-Br and

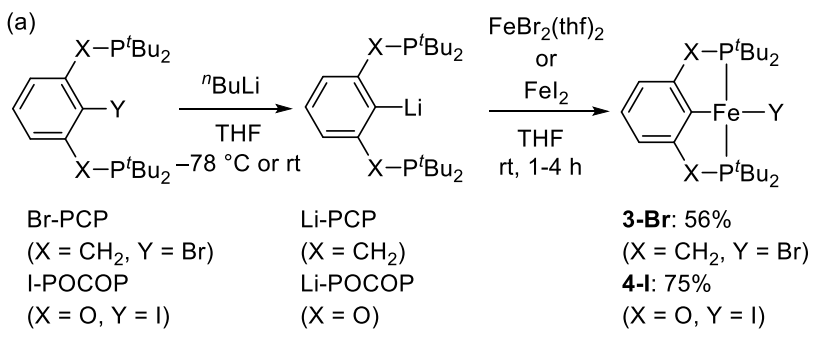

$$
\text { (b) }
$$

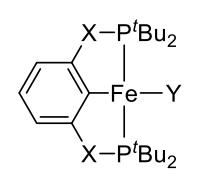

3-Br

$\left(\mathrm{X}=\mathrm{CH}_{2}, \mathrm{Y}=\mathrm{Br}\right)$

4-I

$(X=O, Y=I)$

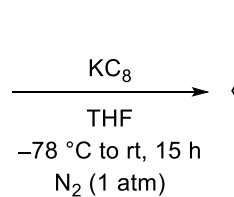
$\mathrm{N}_{2}(1 \mathrm{~atm})$

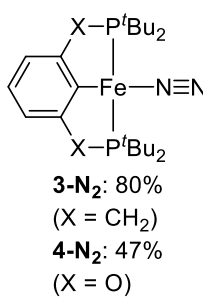

Scheme 1. Synthesis of iron-dinitrogen complexes supported by PCP and POCOP ligands 
4-I. Solution magnetic moments of 3-Br $\left(3.5 \mu_{\mathrm{B}}\right)$ and 4 -I $\left(3.6 \mu_{\mathrm{B}}\right)$ were found to be within the range of those of square-planar Fe(II) complexes with an $S=1$ state. $^{64,65}$

The reaction of 3-Br with 1.1 equiv of $\mathrm{KC}_{8}$ in $\mathrm{THF}$ at room temperature for $15 \mathrm{~h}$ under an atmospheric pressure of dinitrogen produced an iron(I)-dinitrogen complex $\left[\mathrm{Fe}\left(\mathrm{N}_{2}\right)(\mathrm{PCP})\right]\left(\mathbf{3}-\mathrm{N}_{2}\right)$ in $80 \%$ yield. However, the reaction of $4-\mathrm{I}$ with $\mathrm{KC}_{8}$ at room temperature under dinitrogen (1 atm) caused the incomplete conversion of $4-\mathbf{I}$, generating a mixture of $\left[\mathrm{Fe}\left(\mathrm{N}_{2}\right)(\mathrm{POCOP})\right]\left(\mathbf{4}-\mathbf{N}_{2}\right)$ and ${ }^{t} \mathrm{Bu}_{2} \mathrm{PH}$. We also found that the treatment of $4-\mathrm{I}$ with $\mathrm{KC}_{8}$ at $-78{ }^{\circ} \mathrm{C}$ resulted in the clean conversion of 4-I to form $4-\mathbf{N}_{2}$ in $47 \%$ yield. XRD determined the molecular structures of $3-\mathbf{N}_{2}$ and $4-\mathbf{N}_{2}$, and Figure 2 shows their ORTEP drawings. Complexes 3-N2 and 4-N2 demonstrate a distorted squareplanar geometry around the iron center similar to the iron(I)-dinitrogen complexes bearing the pyrrole-based pincer ligands, $\left[\mathrm{Fe}\left(\mathrm{N}_{2}\right)\left({ }^{\mathrm{R}} \mathrm{PNP}\right)\right] \quad\left(\mathbf{1 - N _ { 2 }}, \quad{ }^{\mathrm{H}} \mathrm{PNP}=\right.$ 2,5-bis(di-tertbutylphosphinomethyl)pyrrolide; $\quad \mathbf{2}^{-N_{2}}, \quad{ }^{\text {Me}} \mathrm{PNP} \quad=\quad$ 3,4-dimethyl-2,5-bis(di-tertbutylphosphinomethyl)pyrrolide). ${ }^{57,58} \mathrm{New}$ complexes $\mathbf{3}-\mathbf{N}_{\mathbf{2}}$ and $\mathbf{4 - \mathbf { N } _ { 2 }}$ exhibit comparable N-N distances (1.128(3) and 1.135(6) $\AA$, respectively), which are similar to those of 1-N2 and 2-N2 (Table 1), while the $\mathrm{Fe}-\mathrm{C}$ bond of $\mathbf{3}-\mathbf{N}_{2}(2.000(2))$ is longer than that of $\mathbf{4}-\mathbf{N}_{2}$ (1.961(4) $\AA$ ).
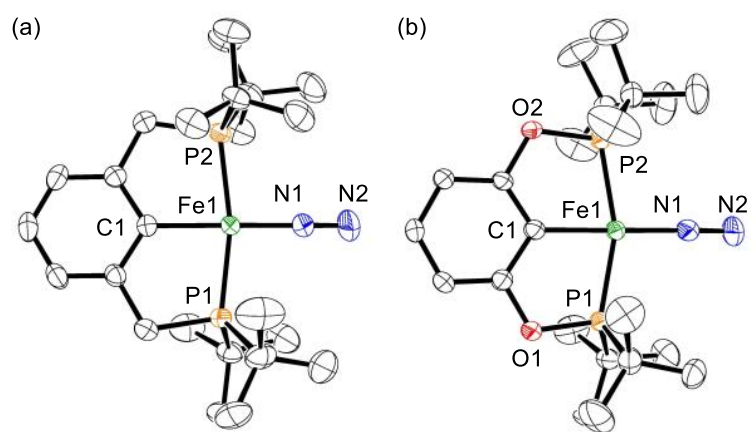

Figure 2. ORTEP drawings of (a) $\mathbf{3}-\mathbf{N}_{2}$ and(b) $4-\mathbf{N}_{2}$. Hydrogen atoms are omitted for clarity. 
Table 1. Bond lengths and dinitrogen stretching frequencies of iron-dinitrogen $\operatorname{complexes}^{a}$

\begin{tabular}{|c|c|c|c|c|}
\hline Complex & $\mathrm{Fe}-\mathrm{N}(\AA)$ & $\mathrm{Fe}-\mathrm{C}(\AA)$ & $\mathrm{N}-\mathrm{N}(\AA)$ & $v_{\mathrm{NN}}\left(\mathrm{cm}^{-1}\right)^{b}$ \\
\hline $3-N_{2}$ & $1.774(2)$ & $2.000(2)$ & $1.128(4)$ & 1954 \\
\hline $4-N_{2}$ & $1.782(4)$ & $1.961(4)$ & $1.135(7)$ & 1978 \\
\hline $1-\mathrm{N}_{2}$ & $1.764(2)$ & & $1.134(2)$ & 1964 \\
\hline $2-\mathrm{N}_{2}$ & $1.758(7)$ & & $1.136(9)$ & 1959 \\
\hline$\left[3-\left(\mathbf{N}_{2}\right)_{2}\right] \mathrm{K}$ & $\begin{array}{l}1.788(3){ }^{c} \\
1.786(3)^{d}\end{array}$ & $2.001(4)$ & $\begin{array}{l}1.133(5){ }^{c} \\
1.147(5)^{d}\end{array}$ & 1981,1894 \\
\hline$\left[3-\left(\mathbf{N}_{2}\right)_{2}\right] \mathbf{N a}$ & $\begin{array}{l}1.780(2){ }^{c} \\
1.826(2)^{d}\end{array}$ & $2.013(2)$ & $\begin{array}{l}1.137(2){ }^{c} \\
1.131(3)^{d}\end{array}$ & 1997,1880 \\
\hline$\left[1-\mathrm{N}_{2}\right] \mathrm{Na}$ & $1.712(3)$ & & $1.169(5)$ & 1831 \\
\hline
\end{tabular}

${ }^{a}$ Data of $\mathbf{1 - N _ { 2 }}$ and $\mathbf{2 - N _ { 2 }}$ are taken from references 57 and $58 .{ }^{b}$ Measured in solid-state (KBr). ${ }^{c}$ Equatorial. ${ }^{d}$ Axial.

The IR spectrum of 3-N $\mathbf{N}_{2}$ in a solid-state $(\mathrm{KBr})$ displays a strong $v_{\mathrm{NN}}$ band at $1954 \mathrm{~cm}^{-1}$, which is smaller than those of $\mathbf{1}-\mathbf{N}_{\mathbf{2}}$ and $\mathbf{2}-\mathbf{N}_{\mathbf{2}}\left(1964\right.$ and $1959 \mathrm{~cm}^{-1}$, respectively). ${ }^{57,58}$ This result suggests that the PCP ligand has a stronger electron-donating ability than the pyrrole-based PNP pincer ligands. On the other hand, the absorption of the dinitrogen ligand in $\mathbf{4 - \mathbf { N } _ { 2 }}$ is observed at $1978 \mathrm{~cm}^{-1}$, indicating a weaker electron-donating nature in this complex. This finding agrees with the study by Goldman and co-workers, who reported on the electron-withdrawing characteristics of the POCOP ligand in iridium complexes compared with the PCP ligand. ${ }^{66}$ Complexes $\mathbf{3}-\mathbf{N}_{\mathbf{2}}$ and $\mathbf{4 - \mathbf { N } _ { 2 }}$ were paramagnetic with solution magnetic moments of 2.7 and $2.5 \mu_{\mathrm{B}}$ at room temperature, respectively. Although these measurements are larger than the spin-only value for an $S=1 / 2$ spin state $\left(1.73 \mu_{\mathrm{B}}\right)$, this value is similar to that of $\mathbf{1 - N _ { 2 }}\left(3.0 \mu_{\mathrm{B}}\right)$, whose spin state is assigned as a doublet. ${ }^{65}$ We consider that the large magnetic moments of $\mathbf{3}-\mathbf{N}_{\mathbf{2}}$ and $\mathbf{4}-\mathbf{N}_{\mathbf{2}}$ are caused by the presence of spin-orbit coupling. ${ }^{65}$

With the dinitrogen complexes in hand, we investigated the catalytic reduction of dinitrogen under the conditions applied during our previous studies, ${ }^{57,58}$ and developed originally by Peters and coworkers. ${ }^{47}$ The reaction of the atmospheric pressure of dinitrogen with $\mathrm{KC}_{8}$ (200 equiv to $\mathbf{3}-\mathbf{N}_{2}$ ) and $\left[\mathrm{H}\left(\mathrm{OEt}_{2}\right)_{2}\right] \mathrm{BAr}_{4}{ }_{4}\left(\mathrm{Ar}^{\mathrm{F}}=3,5-\left(\mathrm{CF}_{3}\right)_{2} \mathrm{C}_{6} \mathrm{H}_{3}, 184\right.$ equiv to $\left.\mathbf{3}-\mathbf{N}_{2}\right)$ in the presence of $\mathbf{3}-\mathbf{N}_{\mathbf{2}}$ as a catalyst in $\mathrm{Et}_{2} \mathrm{O}$ at $-78{ }^{\circ} \mathrm{C}$ for $1 \mathrm{~h}$ provided 7.9 equiv of ammonia and 0.8 equiv of hydrazine, together with 52 equiv of dihydrogen as a byproduct (Table 2 , entry 1 ). As the quantities of reductant and proton source increased, larger amounts of ammonia and hydrazine were produced when $\mathbf{3}-\mathbf{N}_{2}$ was used as a catalyst (Table 2, entries 2-5). When 8000 equiv of $\mathrm{KC}_{8}$ and 7360 equiv of [ $\left.\mathrm{H}\left(\mathrm{OEt}_{2}\right)_{2}\right] \mathrm{BAr}^{\mathrm{F}}{ }_{4}$ were used under the same reaction conditions, a mixture of ammonia and hydrazine ( 252 equiv and 68 equiv based on the iron atom, respectively) was obtained with 1580 equiv of dihydrogen (Table 2, entry 5). With 
smaller amounts of reductant and proton sources, the yields of ammonia and hydrazine obtained by

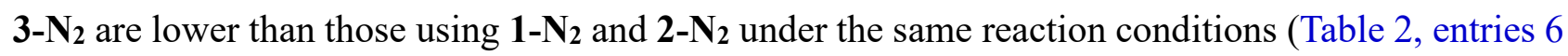
and 8). ${ }^{57,58}$ However, $\mathbf{1}-\mathbf{N}_{\mathbf{2}}$ and $\mathbf{2}-\mathbf{N}_{\mathbf{2}}$ exhibited a lower catalytic activity when we loaded larger amounts of reductant and proton source (Table 2, entries 7 and 9). ${ }^{57,58}$ The use of $\mathbf{3 - \mathbf { N } _ { 2 }}$ as a catalyst affords larger amounts of ammonia and hydrazine than other iron-based catalysts. ${ }^{20-22,48-53}$ We believe that the catalytic activity of $\mathbf{3}-\mathbf{N}_{\mathbf{2}}$ surpasses that of other transition metal complexes for ammonia formation in TONs, ${ }^{38-42,45,46,54-56}$ except for our molybdenum complexes. ${ }^{43,44}$ Only low yields of ammonia and hydrazine were achieved in $9 \%$ and $3 \%$ based on the proton source, respectively (Table 2, entry 5). A substantial amount of hydrogen ( $>40 \%$ ) was observed as a byproduct when 3-N2 was used as a catalyst (Table 2, entry 5). 
Table 2. Catalytic formation of $\mathrm{NH}_{3}$ and $\mathrm{NH}_{2} \mathrm{NH}_{2}$ from $\mathrm{N}_{2}, \mathrm{KC}_{8}$, and $\left[\mathrm{H}\left(\mathrm{OEt}_{2}\right)\right] \mathrm{BAr}{ }_{4}$ by iron complexes as catalysts ${ }^{a}$

\begin{tabular}{|c|c|c|c|c|c|c|c|}
\hline \multicolumn{2}{|r|}{$\mathrm{N}_{2}$} & $\begin{array}{r}\mathrm{KC}_{8} \\
\mathrm{~A}\end{array}$ & $\begin{array}{l}+\left[\mathrm{H}\left(\mathrm{OEt}_{2}\right)_{2}\right] \mathrm{BAr}_{4} \\
\mathrm{~F}=3,5-\left(\mathrm{CF}_{3}\right)_{2} \mathrm{C}_{6} \mathrm{H}_{3}\end{array}$ & $\begin{array}{r}\text { cat. } \\
\mathrm{Et}_{2} \mathrm{O} \\
-78^{\circ} \mathrm{C}, \\
\text { to rt, } 20 \mathrm{r}\end{array}$ & $\mathrm{NH}_{3}+$ & $\mathrm{NH}_{2} \mathrm{NH}_{2}$ & \\
\hline entry & catalyst & $\begin{array}{l}\mathrm{KC}_{8} \\
\text { (equiv) }^{b}\end{array}$ & $\begin{array}{l}{\left[\mathrm{H}\left(\mathrm{OEt}_{2}\right)_{2}\right] \mathrm{BAr}_{4}} \\
\text { (equiv) }^{b}\end{array}$ & $\begin{array}{l}\mathrm{NH}_{3} \\
\text { (equiv) }\end{array}$ & $\begin{array}{l}\mathrm{NH}_{2} \mathrm{NH}_{2} \\
\text { (equiv) }^{b}\end{array}$ & $\begin{array}{l}\text { Fixed } \mathrm{N} \\
\text { (equiv) }^{b, c}\end{array}$ & $\begin{array}{l}\mathrm{H}_{2} \\
\text { (equiv) }^{b}\end{array}$ \\
\hline 1 & $3-\mathrm{N}_{2}$ & 200 & 184 & $7.9 \pm 0.8$ & $0.8 \pm 0.8$ & 9.5 & $52 \pm 3$ \\
\hline 2 & $3-\mathrm{N}_{2}$ & 400 & 368 & $13.3 \pm 1.0$ & $1.2 \pm 0.7$ & 15.7 & $70 \pm 36$ \\
\hline 3 & $3-\mathrm{N}_{2}$ & 800 & 736 & $21.2 \pm 3.9$ & $3.2 \pm 1.5$ & 27.6 & $162 \pm 14$ \\
\hline 4 & $3-\mathrm{N}_{2}$ & 1600 & 1470 & $56.0 \pm 2.0$ & $5.7 \pm 3.3$ & 67.4 & $330 \pm 11$ \\
\hline 5 & $3-\mathrm{N}_{2}$ & 8000 & 7360 & $252 \pm 21$ & $68 \pm 15$ & 388 & $1580 \pm 320$ \\
\hline 6 & $\mathbf{1 - \mathbf { N } _ { 2 }}{ }^{d}$ & 200 & 184 & $14.3 \pm 0.4$ & $1.8 \pm 0.2$ & 17.9 & $12.3 \pm 1.7$ \\
\hline 7 & $\mathbf{1 - \mathbf { N } _ { 2 }}{ }^{d}$ & 400 & 368 & 12.7 & 0.8 & 14.3 & 38.4 \\
\hline 8 & $\mathbf{2}-\mathbf{N}_{2}{ }^{e}$ & 200 & 184 & $22.7 \pm 1.7$ & $1.7 \pm 0.3$ & 26.1 & $21.0 \pm 2.4$ \\
\hline 9 & $2-\mathbf{N}_{2}{ }^{e}$ & 400 & 368 & 17 & 1.9 & 20.8 & 67 \\
\hline 10 & $4-\mathrm{N}_{2}$ & 200 & 184 & $4.6 \pm 1.2$ & $0.3 \pm 0.3$ & 5.2 & $46 \pm 3$ \\
\hline 11 & $4-N_{2}$ & 400 & 368 & $12.4 \pm 0.8$ & $1.8 \pm 0.8$ & 16.0 & $83 \pm 15$ \\
\hline 12 & $4-\mathrm{N}_{2}$ & 800 & 736 & $17.5 \pm 0.7$ & $3.0 \pm 1.0$ & 23.5 & $191 \pm 7$ \\
\hline 13 & $4-N_{2}$ & 1600 & 1470 & $39.7 \pm 9.1$ & $6.2 \pm 1.5$ & 52.1 & $377 \pm 7$ \\
\hline 14 & {$\left[3-\left(\mathbf{N}_{2}\right)_{2}\right] \mathrm{K}$} & 400 & 368 & $7.9 \pm 2.1$ & $0.5 \pm 0.1$ & 8.9 & $88 \pm 23$ \\
\hline 15 & {$\left[3-\left(\mathbf{N}_{2}\right)_{2}\right] \mathrm{Na}$} & 400 & 368 & $14.9 \pm 0.1$ & $0.2 \pm 0.1$ & 15.3 & $86 \pm 3$ \\
\hline 16 & {$\left[1-\mathrm{N}_{2}\right] \mathrm{Na}$} & 400 & 368 & $19.1 \pm 1.3$ & $2.8 \pm 0.8$ & 24.6 & $76 \pm 4$ \\
\hline
\end{tabular}

${ }^{a} \mathrm{~A}$ mixture of catalyst, $\mathrm{KC}_{8}$, and $\left[\mathrm{H}\left(\mathrm{OEt}_{2}\right)_{2}\right] \mathrm{BAr}^{\mathrm{F}}{ }_{4}$ was stirred in $\mathrm{Et}_{2} \mathrm{O}$ at $-78^{\circ} \mathrm{C}$ for $1 \mathrm{~h}$ under $1 \mathrm{~atm}$ of dinitrogen and then at room temperature for $20 \mathrm{~min}$. Averages of multiple runs are shown unless otherwise noted. ${ }^{b}$ Based on the amount of catalyst. ${ }^{c}$ Number of fixed nitrogen atoms (equiv) $=\left[\mathrm{NH}_{3}\right.$ (equiv) $]+2\left[\mathrm{NH}_{2} \mathrm{NH}_{2}\right.$ (equiv)]. ${ }^{d}$ Taken from reference $57 .{ }^{e}$ Taken from reference 58.

For comparison, the catalytic activity of $\mathbf{4 - \mathbf { N } _ { 2 }}$ was examined under identical conditions. As the reductant and proton source increased, larger quantities of ammonia and hydrazine were produced (Table 2, entries 10-13). The reaction of an atmospheric pressure of dinitrogen with $\mathrm{KC}_{8}$ (1600 equiv to $\left.4-\mathbf{N}_{2}\right)$ and $\left[\mathrm{H}\left(\mathrm{OEt}_{2}\right)_{2}\right] \mathrm{BAr}_{4} \mathrm{~F}_{4}\left(1470\right.$ equiv to $\mathbf{4 - \mathbf { N } _ { 2 } )}$ in the presence of $\mathbf{4}-\mathbf{N}_{\mathbf{2}}$ as a catalyst in $\mathrm{Et}_{2} \mathrm{O}$ at $-78{ }^{\circ} \mathrm{C}$ for $1 \mathrm{~h}$ provided 39.7 equiv and 6.2 equiv of ammonia and hydrazine based on the iron atom, respectively (Table 2, entry 13). The amounts of ammonia and hydrazine produced with the 4-N2 complex are higher than those with complexes $\mathbf{1}-\mathbf{N}_{\mathbf{2}}$ and $\mathbf{2}-\mathbf{N}_{\mathbf{2}}$ but lower than those for $\mathbf{3}-\mathbf{N}_{\mathbf{2}}$. We 
suggest that one of the reasons for the lower catalytic activity exhibited by complex 4-N2 compared with complex 3-N $\mathbf{N}_{2}$ is the decomposition of $\mathbf{4}-\mathbf{N}_{2}$ due to the reductive cleavage of the $\mathrm{P}-\mathrm{O}$ bonds in the POCOP ligand.

We consider that the catalytic reaction described in this paper proceeds via the same proposed reaction pathway detailed in our previous study, where iron(0)-dinitrogen and iron-hydrazine complexes work as key reactive intermediates. ${ }^{57}$ To confirm this, we checked the reactivity of hydrazine under the current reaction conditions. In the presence of [FeMe(PCP)] (3-Me), which was prepared from 3-Br and $\mathrm{MeMgBr}$, the reaction of $\left[\mathrm{NH}_{2} \mathrm{NH}_{3}\right] \mathrm{BAr}_{4}{ }_{4}$ (4 equiv to 3-Me) with $\mathrm{KC}_{8}$ (400 equiv to 3-Me) and $\left[\mathrm{H}\left(\mathrm{OEt}_{2}\right)_{2}\right] \mathrm{BAr}_{4}^{\mathrm{F}}\left(368\right.$ equiv to 3-Me) in $\mathrm{Et}_{2} \mathrm{O}$ at $-78{ }^{\circ} \mathrm{C}$ under argon atmosphere provided ammonia in $24 \%$ yield and $48 \%$ recovery of hydrazine. This result implies that hydrazine partially converted to ammonia under the catalytic reaction conditions.

Next, we investigated the reactivity of anionic iron(0)-complexes bearing the PCP ligand. The cyclic voltammogram of $\mathbf{3}-\mathbf{N}_{2}$ displays an irreversible reduction wave at $E_{\mathrm{pc}}=-2.94 \mathrm{~V} \mathrm{vs}$. ferrocene ${ }^{0 /+}$ (Figure S1), indicating that one-electron reduced species of $\mathbf{3}-\mathbf{N}_{\mathbf{2}}$ is accessible. The reduction of 3-N with 2 equiv of $\mathrm{KC}_{8}$ or 10 equiv of $\mathrm{K}$ in $\mathrm{THF}$ at room temperature under dinitrogen caused a color change from green to brown, producing a new diamagnetic complex (Scheme 2a). This new complex was isolated by recrystallization in $36 \%$ yield, and XRD unambiguously confirmed its structure as an anionic iron(0)-bis(dinitrogen) complex $\left[\mathrm{Fe}\left(\mathrm{N}_{2}\right)_{2}(\mathrm{PCP})\right] \mathrm{K}(\mathrm{THF})_{2}\left(\left[\mathbf{3}-\left(\mathbf{N}_{2}\right)_{2}\right] \mathbf{K}\right)$ (Figure 3a). Upon one-electron reduction, the iron center adopts a pentacoordinate structure bearing two terminal dinitrogen ligands with $\tau_{5}$ of 0.45 ( $\tau_{5}=0$ for a perfect square-pyramidal geometry and $\tau_{5}=1$ for a trigonal-bipyramidal geometry). ${ }^{67}$ The equatorial dinitrogen ligand (N1-N2) is coordinated with the potassium cation, which contains two ligated THF molecules and is bound to the axial dinitrogen ligand (N3'-N4') and the benzene ring of the PCP ligand in another molecule. As a result, [3-( $\left.\left.\mathbf{N}_{2}\right)_{2}\right] \mathbf{K}$
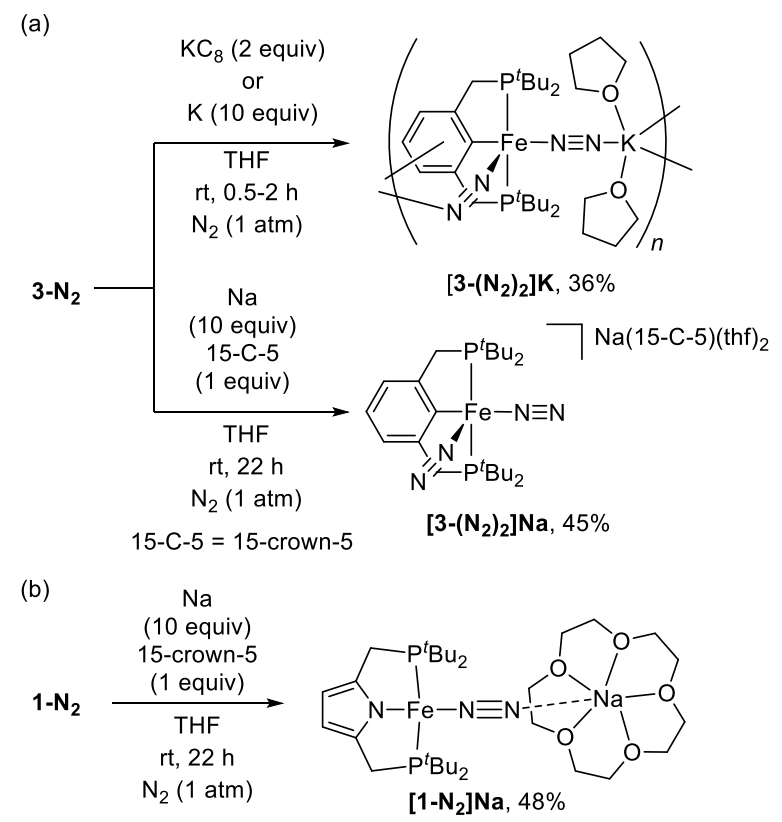

Scheme 2. Synthesis of iron(0)-dinitrogen Complexes bearing the PCP and PNP ligands. 
forms a one-dimensional polymer in the crystal structure. There was no significant change in the Fe-

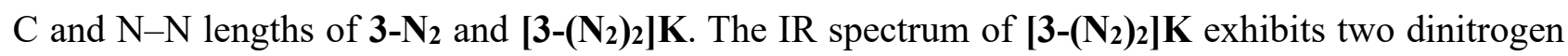
stretching frequencies at 1981 and $1894 \mathrm{~cm}^{-1}$. When $\mathbf{3}-\mathbf{N}_{2}$ was reduced with an excess amount of $\mathrm{Na}$ in the presence of 15-crown-5 (15-C-5) in THF at room temperature under dinitrogen, a diamagnetic iron $(0)$ complex $\left[\mathrm{Fe}\left(\mathrm{N}_{2}\right)_{2}(\mathrm{PCP})\right] \mathrm{Na}(15-\mathrm{C}-5)(\mathrm{THF})_{2}\left(\left[\mathbf{3}-\left(\mathbf{N}_{2}\right)_{2}\right] \mathbf{N a}\right)$ was obtained in $45 \%$ isolated yield (Scheme $2 \mathrm{a}$ ). In the crystal structure, [3-( $\left.\left.\mathbf{N}_{2}\right)_{2}\right] \mathbf{N a}$ also possesses a distorted square-pyramidal iron center $\left(\tau_{5}=0.31\right)$ with two dinitrogen ligands, where the sodium cation is encapsulated by the crown ether and two THF molecules (Figure $4 b$ ). The metric parameters of [3-( $\left.\left.\mathbf{N}_{2}\right)_{2}\right] \mathbf{N a}$ are similar to those of [3-( $\left.\left.\mathbf{N}_{2}\right)_{2}\right] \mathbf{K}$. The IR absorbances derived from the dinitrogen ligands in [3-( $\left.\left.\mathbf{N}_{2}\right)_{2}\right] \mathbf{N a}$ were visible at

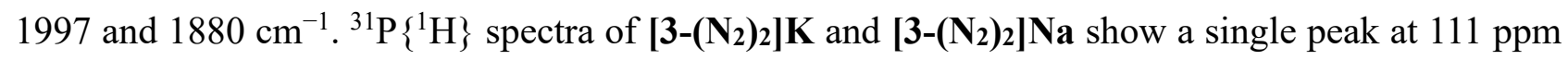
in the temperature range of $25^{\circ} \mathrm{C}$ to $-80{ }^{\circ} \mathrm{C}$ in THF- $d_{8}$ under atmospheric pressure of $\mathrm{N}_{2}$ (Figure $4 \mathrm{a}$ and Figure S11b), which suggests that $\left[3-\left(\mathbf{N}_{2}\right)_{2}\right] \mathbf{K}$ and $\left[3-\left(\mathbf{N}_{2}\right)_{2}\right] \mathbf{N a}$ maintain their five-coordinate structure in solution.

When in situ generated [3-( $\left.\left.\mathbf{N}_{2}\right)_{2}\right] \mathbf{K}$ was treated with one equiv of $\left[\mathrm{H}\left(\mathrm{OEt}_{2}\right)_{2}\right] \mathrm{BAr}_{4}{ }_{4}$ in $\mathrm{Et}_{2} \mathrm{O}$ at $-78{ }^{\circ} \mathrm{C}$, 2a was formed rapidly in 51\% NMR yield together with the formation of dihydrogen. Peters and co-workers reported similar reactions in which the protonation of anionic iron-dinitrogen complexes caused net oxidation of the corresponding complexes. ${ }^{45,68,69}$ The same researchers also observed the formation of a Fe-NNH species as a reactive intermediate at $-135^{\circ} \mathrm{C}$ using a very bulky ligand. ${ }^{70}$ Separately, we confirmed that $\left[\mathbf{3}-\left(\mathbf{N}_{2}\right)_{2}\right] \mathbf{K}$ and $\left[\mathbf{3}-\left(\mathbf{N}_{2}\right)_{2}\right] \mathbf{N a}$ showed a similar catalytic activity toward nitrogen fixation, which was comparable with 3-N2 (Table 1, entries 14 and 15). Unfortunately, there were no further investigations because both anionic complexes [3-( $\left.\left.\mathbf{N}_{2}\right)_{2}\right] \mathbf{K}$ and [3-( $\left.\left.\mathbf{N}_{2}\right)_{2}\right] \mathbf{N a}$ were highly sensitive to trace amounts of water and air and decomposed rapidly to 3-N 2 .

(a)

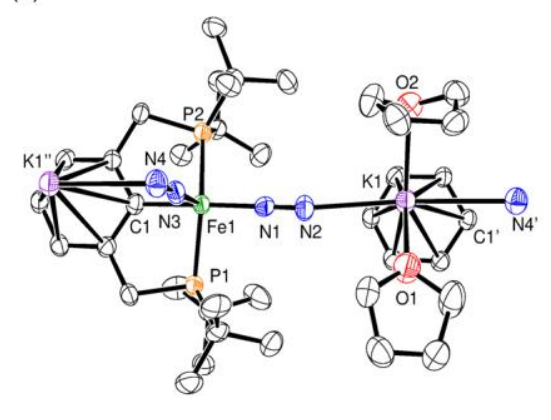

(b)

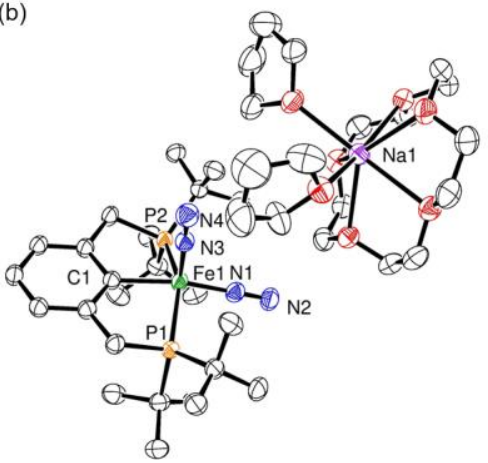

(c)

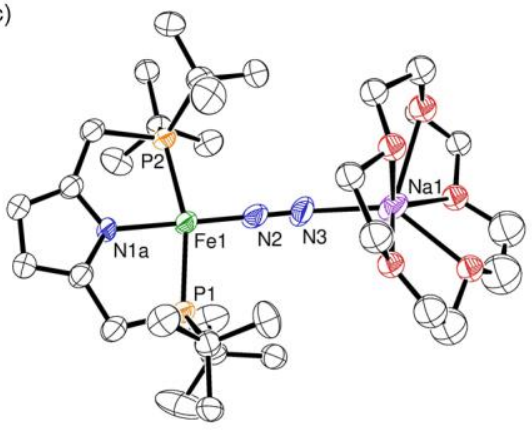

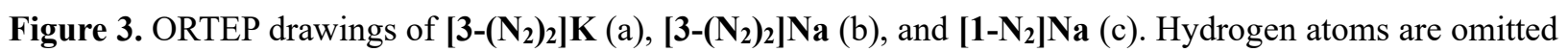
for clarity. 
(a)
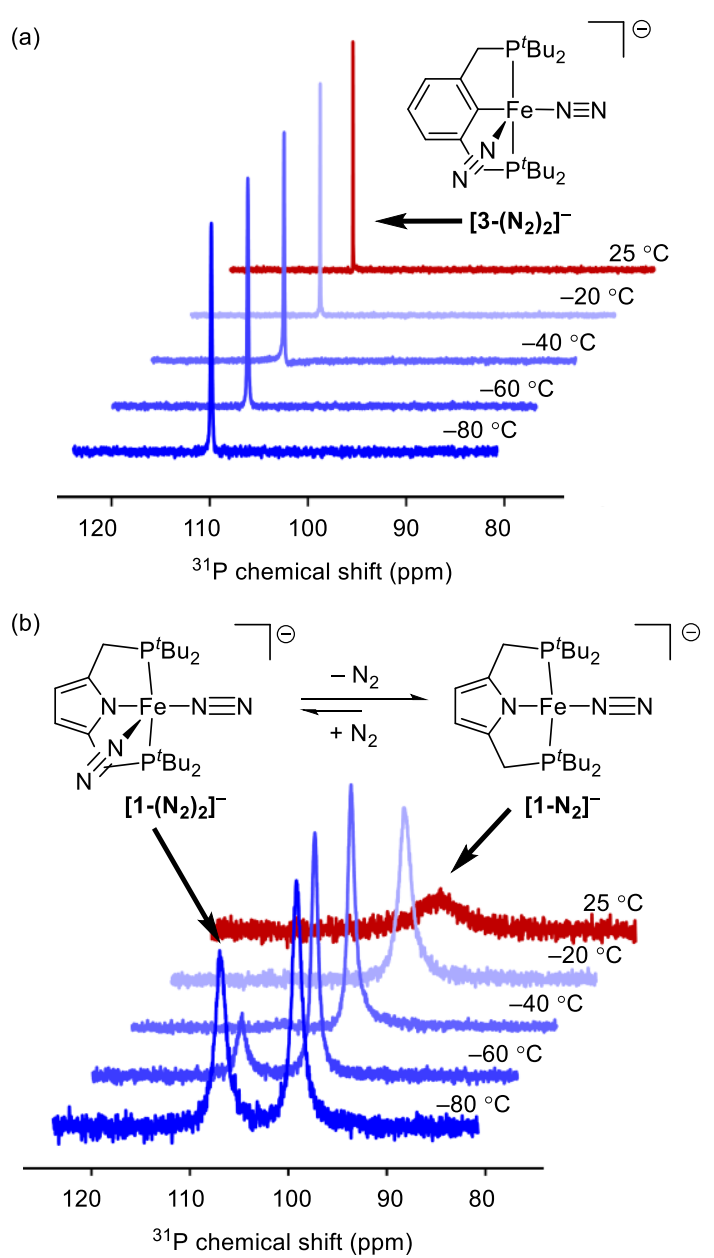

Figure 4. ${ }^{31} \mathrm{P}\left\{{ }^{1} \mathrm{H}\right\}$ NMR spectra of [3-( $\left.\left.\mathbf{N}_{2}\right)_{2}\right] \mathbf{K}$ (a) and [1-

$\left.\mathbf{N}_{2}\right] \mathbf{N a}$ (b) in THF- $d_{8}$ at variable temperature under $\mathrm{N}_{2}(1$

atm) and equilibrium of $\left[\mathbf{1}-\mathbf{N}_{2}\right]^{-}$and $\left[\mathbf{1}-\left(\mathbf{N}_{2}\right)_{2}\right]^{-}$

Our previous study proposed an anionic iron(0)-dinitrogen complex bearing an anionic pyrrolebased PNP-type pincer ligand as a key reactive intermediate, a detailed structure of which was not obtained ${ }^{57}$ Following a comprehensive investigation of the previous results, we successfully obtained a diamagnetic iron(0)-dinitrogen complex $\left[\mathrm{Fe}\left(\mathrm{N}_{2}\right)\left({ }^{\mathrm{H}} \mathrm{PNP}\right)\right] \mathrm{Na}(15-\mathrm{C}-5)\left(\left[\mathbf{1}-\mathrm{N}_{2}\right] \mathbf{N a}\right)$ in $48 \%$ yield from the reaction of $\mathbf{1 - \mathbf { N } _ { 2 }}$ with 10 equiv of $\mathrm{Na}$ and $15-\mathrm{C}-5$ in THF at room temperature for $22 \mathrm{~h}$ under dinitrogen atmosphere (Scheme 2b). The crystal structure of [1-N2] Na reveals that the iron center adopts a distorted square-planar geometry with a terminal dinitrogen ligand binding to $\mathrm{Na}^{+}$(Figure $3 \mathrm{c}$ ). The short $\mathrm{Fe}-\mathrm{N}_{2}$ distance and long $\mathrm{N}-\mathrm{N}$ length imply the strong activation of the dinitrogen ligand, which is supported by a dinitrogen stretching frequency of $1831 \mathrm{~cm}^{-1}$ in the IR spectrum. A ${ }^{31} \mathrm{P}\left\{{ }^{1} \mathrm{H}\right\}$ NMR spectrum of [1-N2]Na exhibits a broad singlet at $100 \mathrm{ppm}$ in THF- $d_{8}$ at $25^{\circ} \mathrm{C}$ under dinitrogen (1 atm). Cooling the solution in situ generates $\left[\mathbf{1}-\mathbf{N}_{2}\right] \mathbf{N a}$ in THF- $d_{8}$ under atmospheric pressure of dinitrogen caused an appearance of a new peak at $110 \mathrm{ppm}$ in the ${ }^{31} \mathrm{P}\left\{{ }^{1} \mathrm{H}\right\} \mathrm{NMR}$ spectrum. In a control experiment under argon atmosphere, the peak at 110 ppm was not observed. Consequently, the new species was assigned as a five-coordinate complex $\left[\mathrm{Fe}\left(\mathrm{N}_{2}\right)_{2}\left({ }^{\mathrm{H}} \mathrm{PNP}\right)\right]^{-}\left(\left[\mathbf{1}-\left(\mathbf{N}_{2}\right)_{2}\right]^{-}\right)$. The ratio 
of $\left[\mathbf{1}-\left(\mathbf{N}_{2}\right)_{2}\right]^{-}$and $\left[\mathbf{1 - N} \mathbf{N}_{2}\right]^{-}$in the complex was found to be approximately 50:50 at $-80{ }^{\circ} \mathrm{C}$. The temperature-dependent change in the NMR spectra was reversible, and the original spectrum was recovered upon warming. Therefore, these results indicate that $\left[\mathbf{1}-\left(\mathbf{N}_{2}\right)_{2}\right]^{-}$and $\left[\mathbf{1 -} \mathbf{N}_{2}\right]^{-}$are in equilibrium in solution, and $\left[\mathbf{1}-\mathbf{N}_{2}\right]^{-}$predominates at higher temperatures, whereas the population of [1-(N $\left.\left.\mathbf{N}_{2}\right)_{2}\right]^{-}$increases at lower temperatures. Such coordination of dinitrogen to iron complexes at low temperatures has been reported in several studies. ${ }^{20,31,71,72}$ The complex [1-N2] Na was employed as a catalyst for the formation of ammonia and hydrazine and exhibited similar catalytic activity to that of 1-N2 (Table 1, entry 16). However, further investigations were complicated by the high sensitivity of $\left[\mathbf{1 - N} \mathbf{N}_{2}\right] \mathbf{N a}$ to air and moisture.

The above experimental results indicate that the structures of the iron(0)-dinitrogen complexes depend on the pincer ligands. The iron(0) PCP complex adopts a pentacoordinate structure bearing two dinitrogen ligands. The PNP-analogue favors a square-planar geometry with one dinitrogen ligand. We performed DFT calculations at the B3LYP-D3 level of theory to discuss an anionic iron(0)-dinitrogen complex suitable for protonation. The Supporting Information provides detailed computational methods and calculated results. Figure 5(a) presents optimized structures of fivecoordinate $\left[3-\left(\mathbf{N}_{2}\right)_{2}\right]^{-}$and four-coordinate $\left[3-\mathbf{N}_{2}\right]^{-}$in the singlet spin state. The calculated geometric parameters of [3-( $\left.\left.\mathbf{N}_{2}\right)_{2}\right]^{-}$satisfactorily replicate the parameters of [3-( $\left.\left.\mathbf{N}_{2}\right)_{2}\right] \mathbf{K}$, as summarized in Table 1. Figure 5(b) displays free energy profiles for the protonation of a dinitrogen ligand of [3-( $\left.\left.\mathbf{N}_{2}\right)_{2}\right]^{-}$and $\left[3-\mathbf{N}_{2}\right]^{-}$. We were unable to optimize a five-coordinate diazenide intermediate $\mathbf{A}$ and found that protonation of the dinitrogen ligand trans to the benzene $C$ atom (equatorial $\mathrm{N}_{2}$ ) in [3-( $\left.\left.\mathbf{N}_{2}\right)_{2}\right]^{-}$caused a spontaneous dissociation of the other dinitrogen ligand (axial $\mathrm{N}_{2}$ ). Conversely, the bond dissociation free energy (BDFE) of the Fe- $\mathrm{N}_{2}$ (axial) bond in [3-( $\left.\left.\mathbf{N}_{2}\right)_{2}\right]^{-}$was calculated to be $9.4 \mathrm{kcal} / \mathrm{mol}$ at 195 $\mathrm{K}$. The protonation of $\left[\mathbf{3}-\mathrm{N}_{2}\right]^{-}$by $\left[\mathrm{H}\left(\mathrm{OEt}_{2}\right)_{2}\right]^{+}$yielding a diazenide intermediate $\mathbf{B}$ proceeds smoothly in an endergonic way $\left(\Delta G_{195}=-37.8 \mathrm{kcal} / \mathrm{mol}\right.$ ) with a low activation barrier of $8.0 \mathrm{kcal} / \mathrm{mol}$ (see details in Figure S13). Therefore, the protonation of $\left[\mathbf{3}-\left(\mathbf{N}_{2}\right)_{2}\right]^{-}$via $\left[3-\mathbf{N}_{2}\right]^{-}$was determined to be highly endergonic by $28.4 \mathrm{kcal} / \mathrm{mol}$. We propose that the active dinitrogen species for nitrogen fixation in the Fe-PCP system adopts a planar four-coordinate structure, which is analogous to the Fe-PNP system. ${ }^{57}$ 

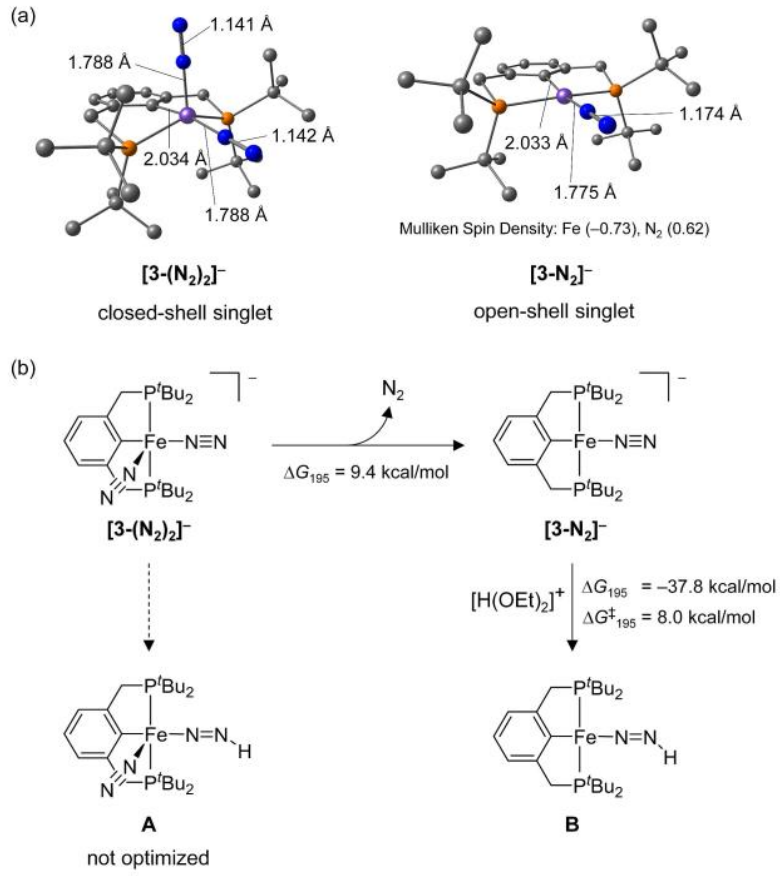

Figure 5. (a) Optimized structures of five-coordinate $\left[3-\left(\mathbf{N}_{2}\right)_{2}\right]^{-}$and four-coordinate $\left[3-\mathbf{N}_{2}\right]^{-}$. (b) Energy profiles calculated for the protonation of $\left[3-\left(\mathbf{N}_{2}\right)_{2}\right]^{-}$and $\left[3-\mathbf{N}_{2}\right]^{-}$.

Next, we theoretically discuss the relative stability of the four- and five-coordinate structures of the anionic iron(0) dinitrogen complexes bearing the PCP and PNP ligands in solution. The temperature dependences of the ${ }^{31} \mathrm{P}-\mathrm{NMR}$ peaks in Figure 4 demonstrate that the $\mathrm{Fe}(\mathrm{PNP})-\mathrm{N}_{2}$ complex favors the four-coordinate structure $\left[\mathbf{1 - \mathbf { N } _ { 2 }}\right]^{-}$at higher temperatures, while the $\mathrm{Fe}(\mathrm{PCP})-\mathrm{N}_{2}$ complex maintains the five-coordinate structure [3-( $\left.\left.\mathbf{N}_{2}\right)_{2}\right]^{-}$. Table 3 summarizes calculated properties

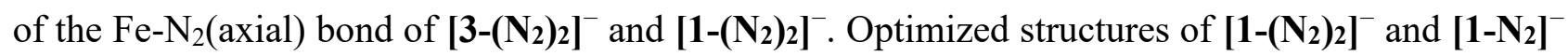
are presented in Figure S14. The BDFE value of the Fe- $\mathrm{N}_{2}$ (axial) bond of [1-( $\left.\left.\mathbf{N}_{2}\right)_{2}\right]^{-}(2.1 \mathrm{kcal} / \mathrm{mol}$ at $195 \mathrm{~K})$ is much smaller than that of $\left[3-\left(\mathbf{N}_{2}\right)_{2}\right]^{-}(9.4 \mathrm{kcal} / \mathrm{mol})$. The Mayer bond orders ${ }^{73}$ of the Fe$\mathrm{N}_{2}$ (axial) bond are 0.92 for $\left[3-\left(\mathbf{N}_{2}\right)_{2}\right]^{-}$and 0.85 for $\left[\mathbf{3}-\left(\mathbf{N}_{2}\right)_{2}\right]^{-}$. The weaker Fe- $\mathrm{N}_{2}$ (axial) bond of [1$\left.\left(\mathbf{N}_{2}\right)_{2}\right]^{-}$can be explained by comparing molecular orbitals responsible for the bonding between the Fe center and axial $\mathrm{N}_{2}$ in $\left[3-\left(\mathbf{N}_{2}\right)_{2}\right]^{-}$and $\left[\mathbf{1 -}\left(\mathbf{N}_{2}\right)_{2}\right]^{-}$. Figure 6 compares HOMO-2 of [3-( $\left.\left.\mathbf{N}_{2}\right)_{2}\right]^{-}$and HOMO-3 of [1-( $\left.\left.\mathbf{N}_{2}\right)_{2}\right]^{-}$, where they are one of two molecular orbitals contributing to $\pi$-back donation (Fe $d_{\mathrm{zx}} \rightarrow \mathrm{N}_{2} \pi^{*}$ ). The back donation from metal to dinitrogen plays a critical role in forming a strong metal-dinitrogen bond. HOMO-2 of [3-( $\left.\left.\mathbf{N}_{2}\right)_{2}\right]^{-}$is localized at the moiety of Fe and two $\mathrm{N}_{2}$ ligands,

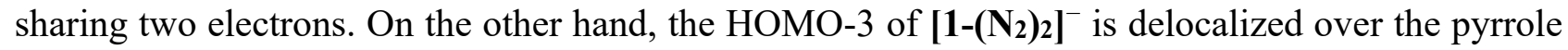
ring of the PNP ligand and the $\mathrm{Fe}\left(\mathrm{N}_{2}\right)_{2}$ moiety. This spatial distribution of HOMO-3 can be associated with a decrease in the number of electrons possessed by the Fe and $\mathrm{N}_{2}$ ligands. The charges of the axial $\mathrm{N}_{2}$ obtained with the natural population analysis $(\mathrm{NPA})^{74}$ are -0.32 for $\left[3-\left(\mathbf{N}_{2}\right)_{2}\right]^{-}$and -0.30 for

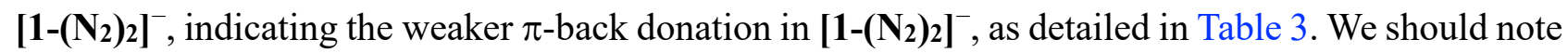


that there was no significant difference between HOMO-1 of $\left[\mathbf{3}-\left(\mathbf{N}_{2}\right)_{2}\right]^{-}$and $\left[\mathbf{1 -}\left(\mathbf{N}_{2}\right)_{2}\right]^{-}$, where HOMO-1 is also the molecular orbital contributing to the $\pi$-back donation from the $d_{\mathrm{yz}}$ orbital of Fe to a $\pi^{*}$ orbital of axial $\mathrm{N}_{2}$ (see Figure $\mathrm{S} 15$ ).

Table 3. Calculated properties of the $\mathrm{Fe}-\mathrm{N}_{2}$ (axial) bond of $\left[3-\left(\mathbf{N}_{2}\right)_{2}\right]^{-}$and $\left[\mathbf{1 -}\left(\mathbf{N}_{2}\right)_{2}\right]^{-}$: Bond dissociation free energy (BDFE) at $195 \mathrm{~K}$, Mayer bond order, and the NPA charge on axial $\mathrm{N}_{2}$.

\begin{tabular}{|c|c|c|}
\hline & {$\left[3-\left(\mathbf{N}_{2}\right)_{2}\right]^{-}$} & {$\left[1-\left(\mathbf{N}_{2}\right)_{2}\right]^{-}$} \\
\hline $\mathrm{BDFE} / \mathrm{kcal} \mathrm{mol}^{-1}$ & 9.4 & 2.1 \\
\hline Mayer bond order & 0.92 & 0.85 \\
\hline NPA charge (axial $N_{2}$ ) & -0.32 & -0.30 \\
\hline
\end{tabular}

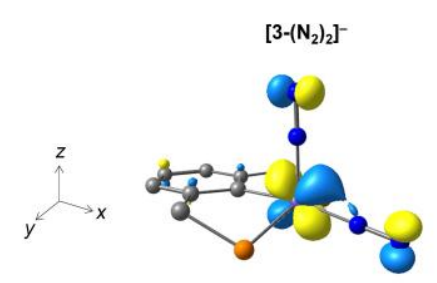

HOMO-2 (-3.54 eV)

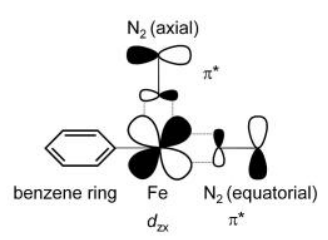

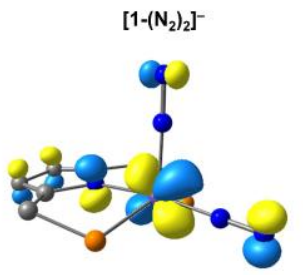

HOMO-3 $(-3.63 \mathrm{eV})$

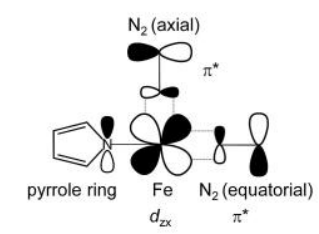

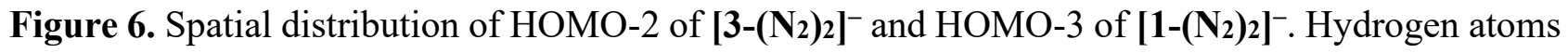
and tert-butyl groups are omitted for clarity.

As the first successful example of an iron catalyst for ammonia formation from dinitrogen under mild reaction conditions, ${ }^{47}$ Peters and co-workers found an iron-dinitrogen complex bearing a triphosphineborane ligand to be an effective catalyst to produce up to 90 equiv of ammonia-based on the iron atom. ${ }^{48,49}$ More recently, Ashley and co-workers reported that an iron-dinitrogen complex supported by diphosphine ligands selectively reduced dinitrogen into hydrazine to give 25 equiv of hydrazine together with 1 equiv of ammonia based on the iron atom. ${ }^{53}$ Although the reaction conditions of both systems are quite different from ours, the amounts of ammonia and hydrazine achieved by the use of the iron-PCP complex are higher than those given by other iron complexes. We consider that the high $\sigma$-donor ability and strong $\mathrm{M}-\mathrm{C}$ bond of the phenyl group ${ }^{75}$ in the PCP complexes may stabilize key intermediates during the catalytic reaction. In addition, the iron-PCP complex with a six-membered backbone of the benzene ring should have better coordination flexibility than the iron-PNP complex with a five-membered backbone of the pyrrole ring. We believe 
that these characteristics of the iron-PCP complex may improve robustness and inhibit deactivation from achieving higher catalytic activity.

In summary, iron(I) - and iron(0)-dinitrogen complexes bearing the PCP and POCOP pincer ligands are the most active catalysts for ammonia and hydrazine formation from dinitrogen under dinitrogen mild reaction conditions. The iron(I)-PCP complex yields the largest amounts of ammonia and hydrazine among the reported iron catalysts, producing up to 252 equiv of ammonia and 68 equiv of hydrazine (388 equiv of fixed $\mathrm{N}$ atom) based on the iron atom of the catalyst. A further mechanistic study is necessary to clarify the reaction pathway and the exact role of the carbon atom in the PCP ligand in catalytic activity. However, our findings demonstrate that the reactive site provided by the benzene-based PCP-type pincer ligand is extremely effective in promoting catalytic nitrogen fixation under mild reaction conditions. We believe that this catalytic activity provides a new opportunity to design more effective model complexes relevant to the active site of nitrogenase.

\section{Acknowledgement}

The present project is supported by CREST, JST (Grant JPMJCR1541). We acknowledge Grants-inAid for Scientific Research (Grants JP20H05671, JP20K21203, and JP20K15295) from JSPS and MEXT. 
References

1. Hoffman, B. M., Lukoyanov, D., Yang, Z.-Y., Dean, D. R. \& Seefeldt, L. C. Mechanism of Nitrogen Fixation by Nitrogenase: The Next Stage. Chem. Rev. 114, 4041-4062 (2014).

2. Lancaster, K. M., Roemelt, M., Ettenhuber, P., Hu, Y., Ribbe, M. W., Neese, F., Bergmann, U. \& DeBeer, S. X-ray Emission Spectroscopy Evidences a Central Carbon in the Nitrogenase IronMolybdenum Cofactor. Science 334, 974-977 (2011).

3. Einsle, O., Tezcan, F. A., Andrade, S. L. A., Schmid, B., Yoshida, M., Howard, J. B. \& Rees, D. C. Nitrogenase MoFe-Protein at $1.16 \AA$ Resolution: A Central Ligand in the FeMo-Cofactor. Science 297, 1696-1700 (2002).

4. Spatzal, T., Aksoyoglu, M., Zhang, L., Andrade, S. L. A., Schleicher, E., Weber, S., Rees, D. C. \& Einsle, O. Evidence for Interstitial Carbon in Nitrogenase FeMo Cofactor. Science 334, 940 940 (2011).

5. Wiig, J. A., Lee, C. C., Hu, Y. \& Ribbe, M. W. Tracing the Interstitial Carbide of the Nitrogenase Cofactor during Substrate Turnover. J. Am. Chem. Soc. 135, 4982-4983 (2013).

6. Rees, J. A., Bjornsson, R., Kowalska, J. K., Lima, F. A., Schlesier, J., Sippel, D., Weyhermüller, T., Einsle, O., Kovacs, J. A. \& DeBeer, S. Comparative electronic structures of nitrogenase FeMoco and FeVco. Dalton Trans. 46, 2445-2455 (2017).

7. Spatzal, T., Perez, K. A., Einsle, O., Howard, J. B. \& Rees, D. C. Ligand binding to the FeMo-cofactor: Structures of CO-bound and reactivated nitrogenase. Science 345, 1620-1623 (2014). 8. Spatzal, T., Perez, K. A., Howard, J. B. \& Rees, D. C. Catalysis-dependent selenium incorporation and migration in the nitrogenase active site iron-molybdenum cofactor. eLife 4, e11620 (2015).

9. Sippel, D., Rohde, M., Netzer, J., Trncik, C., Gies, J., Grunau, K., Djurdjevic, I., Decamps, L., Andrade, S. L. A. \& Einsle, O. A bound reaction intermediate sheds light on the mechanism of nitrogenase. Science 359, 1484-1489 (2018).

10. Benediktsson, B., Thorhallsson, A. Th. \& Bjornsson, R. QM/MM calculations reveal a bridging hydroxo group in a vanadium nitrogenase crystal structure. Chem. Commun. 54, 7310-7313 (2018).

11. Buscagan, T. M., Perez, K. A., Maggiolo, A. O., Rees, D. C. \& Spatzal, T. Structural Characterization of Two CO Molecules Bound to the Nitrogenase Active Site. Angew. Chem. Int. Ed. 60, 5704-5707 (2021).

12. Kang, W., Lee, C. C., Jasniewski, A. J., Ribbe, M. W. \& Hu, Y. Structural evidence for a dynamic metallocofactor during $\mathrm{N}_{2}$ reduction by Mo-nitrogenase. Science 368, 1381-1385 (2020).

13. Peters, J. W., Einsle, O., Dean, D. R., DeBeer, S., Hoffman, B. M., Holland, P. L. \& Seefeldt, L. C. Comment on "Structural evidence for a dynamic metallocofactor during $\mathrm{N}_{2}$ reduction by Monitrogenase". Science 371, eabe5481 (2021).

14. Bergmann, J., Oksanen, E. \& Ryde, U. Critical evaluation of a crystal structure of nitrogenase with bound $\mathrm{N}_{2}$ ligands. JBIC J. Biol. Inorg. Chem. 26, 341-353 (2021). 
15. Črić, I. \& Holland, P. L. Insight into the Iron-Molybdenum Cofactor of Nitrogenase from Synthetic Iron Complexes with Sulfur, Carbon, and Hydride Ligands. J. Am. Chem. Soc. 138, 72007211 (2016).

16. Danopoulos, A. A., Wright, J. A. \& Motherwell, W. B. Molecular $\mathrm{N}_{2}$ complexes of iron stabilised by N-heterocyclic 'pincer' dicarbene ligands. Chem Commun 784-786 (2005).

17. Ohki, Y., Hatanaka, T. \& Tatsumi, K. C-H Bond Activation of Heteroarenes Mediated by a Half-Sandwich Iron Complex of N-Heterocyclic Carbene. J. Am. Chem. Soc. 130, 17174-17186 (2008).

18. Yu, R. P., Hesk, D., Rivera, N., Pelczer, I. \& Chirik, P. J. Iron-catalysed tritiation of pharmaceuticals. Nature 529, 195-199 (2016).

19. Rittle, J. \& Peters, J. C. Fe-N $2 /$ CO complexes that model a possible role for the interstitial C atom of FeMo-cofactor (FeMoco). Proc. Natl. Acad. Sci. 110, 15898-15903 (2013).

20. Ung, G. \& Peters, J. C. Low-Temperature $\mathrm{N}_{2}$ Binding to Two-Coordinate $\mathrm{L}_{2} \mathrm{Fe}^{0}$ Enables Reductive Trapping of $\mathrm{L}_{2} \mathrm{FeN}_{2}{ }^{-}$and $\mathrm{NH}_{3}$ Generation. Angew. Chem. Int. Ed. 54, 532-535 (2014).

21. Creutz, S. E. \& Peters, J. C. Catalytic Reduction of $\mathrm{N}_{2}$ to $\mathrm{NH}_{3}$ by an $\mathrm{Fe}-\mathrm{N}_{2}$ Complex Featuring a C-Atom Anchor. J. Am. Chem. Soc. 136, 1105-1115 (2014).

22. Del Castillo, T. J., Thompson, N. B. \& Peters, J. C. A Synthetic Single-Site Fe Nitrogenase: High Turnover, Freeze-Quench ${ }^{57} \mathrm{Fe}$ Mössbauer Data, and a Hydride Resting State. J. Am. Chem. Soc. 138, 5341-5350 (2016).

23. Čorić, I., Mercado, B. Q., Bill, E., Vinyard, D. J. \& Holland, P. L. Binding of dinitrogen to an iron-sulfur-carbon site. Nature 526, 96-99 (2015).

24. Ouyang, Z., Cheng, J., Li, L., Bao, X. \& Deng, L. High-Spin Iron(I) and Iron(0) Dinitrogen Complexes Supported by N-Heterocyclic Carbene Ligands. Chem. - Eur. J. 22, 14162-14165 (2016). 25. Bai, Y., Zhang, J. \& Cui, C. An arene-tethered silylene ligand enabling reversible dinitrogen binding to iron and catalytic silylation. Chem. Commun. 54, 8124-8127 (2018).

26. Speelman, A. L., Čorić, I., Van Stappen, C., DeBeer, S., Mercado, B. Q. \& Holland, P. L. Nitrogenase-Relevant Reactivity of a Synthetic Iron-Sulfur-Carbon Site. J. Am. Chem. Soc. 141, 13148-13157 (2019).

27. Jackson, B. J., Najera, D. C., Matson, E. M., Woods, T. J., Bertke, J. A. \& Fout, A. R. Synthesis and Characterization of $\left({ }^{\mathrm{DIPP}} \mathrm{CCC}\right) \mathrm{Fe}$ Complexes: A Zwitterionic Metalation Method and $\mathrm{CO}_{2}$ Reactivity. Organometallics 38, 2943-2952 (2019).

28. Reiners, M., Baabe, D., Münster, K., Zaretzke, M.-K., Freytag, M., Jones, P. G., Coppel, Y., Bontemps, S., del Rosal, I., Maron, L. \& Walter, M. D. $\mathrm{NH}_{3}$ formation from $\mathrm{N}_{2}$ and $\mathrm{H}_{2}$ mediated by molecular tri-iron complexes. Nat. Chem. 12, 740-746 (2020).

29. Arnett, C. H. \& Agapie, T. Activation of an Open Shell, Carbyne-Bridged Diiron Complex Toward Binding of Dinitrogen. J. Am. Chem. Soc. 142, 10059-10068 (2020).

30. Li, S., Wang, Y., Yang, W., Li, K., Sun, H., Li, X., Fuhr, O. \& Fenske, D. N 2 Silylation Catalyzed by a Bis(silylene)-Based [SiCSi] Pincer Hydrido Iron(II) Dinitrogen Complex. Organometallics 39, 757-766 (2020). 
31. Nagelski, A. L., Fataftah, M. S., Bollmeyer, M. M., McWilliams, S. F., MacMillan, S. N., Mercado, B. Q., Lancaster, K. M. \& Holland, P. L. The influences of carbon donor ligands on biomimetic multi-iron complexes for $\mathrm{N}_{2}$ reduction. Chem. Sci. 11, 12710-12720 (2020).

32. Speelman, A. L., Skubi, K. L., Mercado, B. Q. \& Holland, P. L. Synthesis and Reactivity of Iron Complexes with a Biomimetic SCS Pincer Ligand. Inorg. Chem. 60, 1965-1974 (2021).

33. Chalkley, M. J., Drover, M. W. \& Peters, J. C. Catalytic $\mathrm{N}_{2}-$ to- $\mathrm{NH}_{3}\left(\right.$ or $\left.-\mathrm{N}_{2} \mathrm{H}_{4}\right)$ Conversion by Well-Defined Molecular Coordination Complexes. Chem. Rev. 120, 5582-5636 (2020).

34. Masero, F., Perrin, M. A., Dey, S. \& Mougel, V. Dinitrogen Fixation: Rationalizing Strategies Utilizing Molecular Complexes. Chem. - Eur. J. 27, 3892-3928 (2021).

35. Ashida, Y. \& Nishibayashi, Y. Catalytic conversion of nitrogen molecule into ammonia using molybdenum complexes under ambient reaction conditions. Chem. Commun. 57, 1176-1189 (2021).

36. Kuriyama, S. \& Nishibayashi, Y. Development of catalytic nitrogen fixation using transition metal complexes not relevant to nitrogenases. Tetrahedron 83, 131986 (2021).

37. Tanabe, Y. \& Nishibayashi, Y. Comprehensive insights into synthetic nitrogen fixation assisted by molecular catalysts under ambient or mild conditions. Chem. Soc. Rev. 50, 5201-5242 (2021).

38. Doyle, L. R., Wooles, A. J., Jenkins, L. C., Tuna, F., McInnes, E. J. L. \& Liddle, S. T. Catalytic Dinitrogen Reduction to Ammonia at a Triamidoamine-Titanium Complex. Angew. Chem. Int. Ed. 57, 6314-6318 (2018).

39. Sekiguchi, Y., Arashiba, K., Tanaka, H., Eizawa, A., Nakajima, K., Yoshizawa, K. \& Nishibayashi, Y. Catalytic Reduction of Molecular Dinitrogen to Ammonia and Hydrazine Using Vanadium Complexes. Angew. Chem. Int. Ed. 57, 9064-9068 (2018).

40. Yandulov, D. V. \& Schrock, R. R. Catalytic Reduction of Dinitrogen to Ammonia at a Single Molybdenum Center. Science 301, 76-78 (2003).

41. Arashiba, K., Miyake, Y. \& Nishibayashi, Y. A molybdenum complex bearing PNP-type pincer ligands leads to the catalytic reduction of dinitrogen into ammonia. Nat. Chem. 3, 120-125 (2011).

42. Eizawa, A., Arashiba, K., Tanaka, H., Kuriyama, S., Matsuo, Y., Nakajima, K., Yoshizawa, K. \& Nishibayashi, Y. Remarkable catalytic activity of dinitrogen-bridged dimolybdenum complexes bearing NHC-based PCP-pincer ligands toward nitrogen fixation. Nat. Commun. 8, 14874 (2017).

43. Arashiba, K., Eizawa, A., Tanaka, H., Nakajima, K., Yoshizawa, K. \& Nishibayashi, Y. Catalytic Nitrogen Fixation via Direct Cleavage of Nitrogen-Nitrogen Triple Bond of Molecular Dinitrogen under Ambient Reaction Conditions. Bull. Chem. Soc. Jpn. 90, 1111-1118 (2017).

44. Ashida, Y., Arashiba, K., Nakajima, K. \& Nishibayashi, Y. Molybdenum-catalysed ammonia production with samarium diiodide and alcohols or water. Nature 568, 536-540 (2019).

45. Ashida, Y., Egi, A., Arashiba, K., Tanaka, H., Kuriyama, S., Yoshizawa, K. \& Nishibayashi, Y. Catalytic Reduction of Dinitrogen into Ammonia and Hydrazine Using Chromium Complexes Bearing PCP-Type Pincer Ligand. ChemRxiv (2021). doi:10.33774/chemrxiv-2021-43mww 
46. Meng, F., Kuriyama, S., Tanaka, H., Egi, A., Yoshizawa, K. \& Nishibayashi, Y. Ammonia Formation Catalyzed by a Dinitrogen-Bridged Dirhenium Complex Bearing PNP-Pincer Ligands under Mild Reaction Conditions. Angew. Chem. Int. Ed. 60, 13906-13912 (2021).

47. Anderson, J. S., Rittle, J. \& Peters, J. C. Catalytic conversion of nitrogen to ammonia by an iron model complex. Nature 501, 84-87 (2013).

48. Chalkley, M. J., Del Castillo, T. J., Matson, B. D., Roddy, J. P. \& Peters, J. C. Catalytic N2to- $\mathrm{NH}_{3}$ Conversion by $\mathrm{Fe}$ at Lower Driving Force: A Proposed Role for Metallocene-Mediated PCET. ACS Cent. Sci. 3, 217-223 (2017).

49. Buscagan, T. M., Oyala, P. H. \& Peters, J. C. $\mathrm{N}_{2}$-to-NH 3 Conversion by a triphos-Iron Catalyst and Enhanced Turnover under Photolysis. Angew. Chem. Int. Ed. 56, 6921-6926 (2017).

50. Chalkley, M. J., Del Castillo, T. J., Matson, B. D. \& Peters, J. C. Fe-Mediated Nitrogen Fixation with a Metallocene Mediator: Exploring $\mathrm{p} K_{\mathrm{a}}$ Effects and Demonstrating Electrocatalysis. $J$. Am. Chem. Soc. 140, 6122-6129 (2018).

51. Dorantes, M. J., Moore, J. T., Bill, E., Mienert, B. \& Lu, C. C. Bimetallic iron-tin catalyst for $\mathrm{N}_{2}$ to $\mathrm{NH}_{3}$ and a silyldiazenido model intermediate. Chem. Commun. 56, 11030-11033 (2020).

52. Fajardo Jr, J. \& Peters, J. C. Tripodal $\mathrm{P}_{3}{ }^{\mathrm{X}} \mathrm{Fe}-\mathrm{N}_{2}$ Complexes $(\mathrm{X}=\mathrm{B}, \mathrm{Al}, \mathrm{Ga})$ : Effect of the Apical Atom on Bonding, Electronic Structure, and Catalytic $\mathrm{N}_{2}$-to- $\mathrm{NH}_{3}$ Conversion. Inorg. Chem. 60, 1220-1227 (2021).

53. Hill, P. J., Doyle, L. R., Crawford, A. D., Myers, W. K. \& Ashley, A. E. Selective Catalytic Reduction of $\mathrm{N}_{2}$ to $\mathrm{N}_{2} \mathrm{H}_{4}$ by a Simple Fe Complex. J. Am. Chem. Soc. 138, 13521-13524 (2016).

54. Fajardo Jr, J. \& Peters, J. C. Catalytic Nitrogen-to-Ammonia Conversion by Osmium and Ruthenium Complexes. J. Am. Chem. Soc. 139, 16105-16108 (2017).

55. Del Castillo, T. J., Thompson, N. B., Suess, D. L. M., Ung, G. \& Peters, J. C. Evaluating Molecular Cobalt Complexes for the Conversion of $\mathrm{N}_{2}$ to $\mathrm{NH}_{3}$. Inorg. Chem. 54, 9256-9262 (2015). 56. Kuriyama, S., Arashiba, K., Tanaka, H., Matsuo, Y., Nakajima, K., Yoshizawa, K. \& Nishibayashi, Y. Direct Transformation of Molecular Dinitrogen into Ammonia Catalyzed by Cobalt Dinitrogen Complexes Bearing Anionic PNP Pincer Ligands. Angew. Chem. Int. Ed. 55, 1429114295 (2016).

57. Kuriyama, S., Arashiba, K., Nakajima, K., Matsuo, Y., Tanaka, H., Ishii, K., Yoshizawa, K. \& Nishibayashi, Y. Catalytic transformation of dinitrogen into ammonia and hydrazine by irondinitrogen complexes bearing pincer ligand. Nat. Commun. 7, 12181 (2016).

58. Sekiguchi, Y., Kuriyama, S., Eizawa, A., Arashiba, K., Nakajima, K. \& Nishibayashi, Y. Synthesis and reactivity of iron-dinitrogen complexes bearing anionic methyl- and phenylsubstituted pyrrole-based PNP-type pincer ligands toward catalytic nitrogen fixation. Chem. Commun. 53, 12040-12043 (2017).

59. Wang, D. Y., Choliy, Y., Haibach, M. C., Hartwig, J. F., Krogh-Jespersen, K. \& Goldman, A. S. Assessment of the Electronic Factors Determining the Thermodynamics of "Oxidative Addition" of C-H and N-H Bonds to $\operatorname{Ir}(\mathrm{I})$ Complexes. J. Am. Chem. Soc. 138, 149-163 (2016).

60. Creaser, C. S. \& Kaska, W. C. Complexes of 1,3-bis(dimethylphosphinomethyl)benzene 
with nickel(II), paladium(II) and iron(II) halides. Inorg. Chim. Acta 30, L325-L326 (1978).

61. Jiang, S., Quintero-Duque, S., Roisnel, T., Dorcet, V., Grellier, M., Sabo-Etienne, S., Darcel, C. \& Sortais, J.-B. Direct synthesis of dicarbonyl PCP-iron hydride complexes and catalytic dehydrogenative borylation of styrene. Dalton Trans. 45, 11101-11108 (2016).

62. Bhattacharya, P., Krause, J. A. \& Guan, H. Mechanistic Studies of Ammonia Borane Dehydrogenation Catalyzed by Iron Pincer Complexes. J. Am. Chem. Soc. 136, 11153-11161 (2014). 63. Dauth, A., Gellrich, U., Diskin-Posner, Y., Ben-David, Y. \& Milstein, D. The FerraquinoneFerrahydroquinone Couple: Combining Quinonic and Metal-Based Reactivity. J. Am. Chem. Soc. 139, 2799-2807 (2017).

64. Hawrelak, E. J., Bernskoetter, W. H., Lobkovsky, E., Yee, G. T., Bill, E. \& Chirik, P. J. Square Planar vs Tetrahedral Geometry in Four Coordinate Iron(II) Complexes. Inorg. Chem. 44, 3103-3111 (2005).

65. Ehrlich, N., Kreye, M., Baabe, D., Schweyen, P., Freytag, M., Jones, P. G. \& Walter, M. D. Synthesis and Electronic Ground-State Properties of Pyrrolyl-Based Iron Pincer Complexes: Revisited. Inorg. Chem. 56, 8415-8422 (2017).

66. Zhu, K., Achord, P. D., Zhang, X., Krogh-Jespersen, K. \& Goldman, A. S. Highly Effective Pincer-Ligated Iridium Catalysts for Alkane Dehydrogenation. DFT Calculations of Relevant Thermodynamic, Kinetic, and Spectroscopic Properties. J. Am. Chem. Soc. 126, 13044-13053 (2004). 67. Addison, A. W., Rao, T. N., Reedijk, J., van Rijn, J. \& Verschoor, G. C. Synthesis, Structure, and Spectroscopic Properties of Copper(II) Compounds containing Nitrogen-Sulphur Donor Ligands; the Crystal and Molecular Structure of Aqua[1,7-bis(N-methylbenzimidazol-2'-yl)-2,6dithiaheptane]copper(II) Perchlorate. J. Chem. Soc. Dalton Trans. 1349-1356 (1984).

68. Anderson, J. S., Cutsail, G. E., Rittle, J., Connor, B. A., Gunderson, W. A., Zhang, L., Hoffman, B. M. \& Peters, J. C. Characterization of an $\mathrm{Fe} \equiv \mathrm{N}-\mathrm{NH}_{2}$ Intermediate Relevant to Catalytic $\mathrm{N}_{2}$ Reduction to $\mathrm{NH}_{3}$. J. Am. Chem. Soc. 137, 7803-7809 (2015).

69. Rittle, J. \& Peters, J. C. An Fe-N 2 Complex That Generates Hydrazine and Ammonia via $\mathrm{Fe}=\mathrm{NNH}_{2}$ : Demonstrating a Hybrid Distal-to-Alternating Pathway for $\mathrm{N}_{2}$ Reduction. J. Am. Chem. Soc. 138, 4243-4248 (2016).

70. Nesbit, M. A., Oyala, P. H. \& Peters, J. C. Characterization of the Earliest Intermediate of Fe- $\mathrm{N}_{2}$ Protonation: $\mathrm{CW}$ and Pulse EPR Detection of an Fe-NNH Species and Its Evolution to Fe$\mathrm{NNH}_{2}^{+}$. J. Am. Chem. Soc. 141, 8116-8127 (2019).

71. McWilliams, S. F., Broere, D. L. J., Halliday, C. J. V., Bhutto, S. M., Mercado, B. Q. \& Holland, P. L. Coupling dinitrogen and hydrocarbons through aryl migration. Nature 584, 221-226 (2020).

72. Rittle, J., McCrory, C. C. L. \& Peters, J. C. A $10^{6}$-Fold Enhancement in $\mathrm{N}_{2}$-Binding Affinity of an $\mathrm{Fe}_{2}(\mu-\mathrm{H})_{2}$ Core upon Reduction to a Mixed-Valence Fe ${ }^{\mathrm{II}} \mathrm{Fe}^{\mathrm{I}}$ State. J. Am. Chem. Soc. 136, 13853-13862 (2014).

73. Mayer, I. Charge, bond order and valence in the AB initio SCF theory. Chem. Phys. Lett. 97, 270-274 (1983). 
74. Glendening, E. D. et al. NBO 5.9 (Theor. Chem. Inst. Univ. Wis. Madison, 2009).

75. Clot, E., Mégret, C., Eisenstein, O. \& Perutz, R. N. Validation of the $\mathrm{M}-\mathrm{C} / \mathrm{H}-\mathrm{C}$ Bond Enthalpy Relationship through Application of Density Functional Theory. J. Am. Chem. Soc. 128, 8350-8357 (2006). 